\title{
(6) OPEN ACCESS \\ Socioeconomic gradients in all-cause, premature and avoidable mortality among immigrants and long-term residents using linked death records in Ontario, Canada
}

\author{
Anam M Khan, ${ }^{1,2}$ Marcelo Urquia, ${ }^{1,2,3}$ Kathy Kornas, ${ }^{1}$ David Henry, ${ }^{1,2}$ \\ Stephanie Y Cheng, ${ }^{2}$ Catherine Bornbaum, ${ }^{1,4}$ Laura C Rosella ${ }^{1,2,5}$
}

\begin{abstract}
- Additional material is published online only. To view please visit the journal online (http://dx.doi.org/10.1136/ jech-2016-208525)

'Dalla Lana School of Public Health, University of Toronto Toronto, Ontario, Canada Institute for Clinical Evaluative Sciences, Toronto, Ontario, Canada

${ }^{3}$ Centre for Inner City Health, Keenan Research Centre, Li Ka Shing Knowledge Institute, St. Michael's Hospital, Toronto, Ontario, Canada

${ }^{4}$ Department of Health \& Rehabilitation Sciences, Faculty of Health Sciences, Western University, London, Ontario,

Canada

${ }^{5}$ Public Health Ontario, Toronto, Ontario, Canada
\end{abstract}

Correspondence to Dr Laura Rosella, Dalla Lana School of Public Health, Health Sciences Building 6th floor, 155 College Street Toronto, Ontario, Canada M5T 3M7:

laura.rosella@utoronto.ca

Received 17 October 2016 Revised 9 January 2017 Accepted 29 January 2017 Published Online First 10 March 2017

\section{ABSTRACT \\ Background Immigrants have been shown to possess a health advantage, yet are also more likely to reside in arduous economic conditions. Little is known about if and how the socioeconomic gradient for all-cause, premature and avoidable mortality differs according to immigration status.}

Methods Using several linked population-based vital and demographic databases from Ontario, we examined a cohort of all deaths in the province between 2002 and 2012. We constructed count models, adjusted for relevant covariates, to attain age-adjusted mortality rates and rate ratios for all-cause, premature and avoidable mortality across income quintile in immigrants and longterm residents, stratified by sex.

Results A downward gradient in age-adjusted all-cause mortality was observed with increasing income quintile, in immigrants (males: Q5: 13.32, Q1: 20.18; females: Q5: 9.88, Q1: 12.51) and long-term residents (males: Q5: 33.25, Q1: 57.67; females: Q5: 22.31, Q1: 36.76). Comparing the lowest and highest income quintiles, male and female immigrants had a $56 \%$ and $28 \%$ lower all-cause mortality rate, respectively. Similar trends were observed for premature and avoidable mortality. Although immigrants had consistently lower mortality rates compared with long-term residents, trends only differed statistically across immigration status for females $(p<0.05)$.

Conclusions This study illustrated the presence of income disparities as it pertains to all-cause, premature, and avoidable mortality, irrespective of immigration status. Additionally, the immigrant health advantage was observed and income disparities were less pronounced in immigrants compared with long-term residents. These findings support the need to examine the factors that drive inequalities in mortality within and across immigration status.

\section{INTRODUCTION}

In 2011 , there were $\sim 6.8$ million immigrants living in Canada, about half of whom were living in the province of Ontario. ${ }^{1}$ Several studies have shown that immigrants are healthier than Canadian-born residents $^{2-6}$ having lower all-cause and causespecific mortality rates, ${ }^{7} 8$ and longer life expectancy. $^{7}$

Several reasons have been proposed for the immigrant health advantage including those in poor health being denied entry due to requirements in Canada's Immigration Act, those in superior health and financially able, self-selecting into the immigration process, and having culturally ingrained protective and healthy lifestyle behaviours. ${ }^{2} 5{ }^{8}-10$ Differences in avoidable mortality are an indicator of inequitable access and use of healthcare services and prevention strategies. ${ }^{11}$ In a recent study, the immigrant health advantage was shown to extend partially to avoidable mortality, in that mortality rates from several preventable and treatable causes were estimated to be lower among immigrants compared with non-immigrants. ${ }^{12}$

In contrast to their health advantage, recent research has shown an income gap between immigrants and Canadian-born residents. ${ }^{13}$ Recent immigrants were 2.6 times more likely to be classified as low-income, relative to non-immigrants, ${ }^{13}$ and the gap has been relatively unchanged from the year $2000 .^{13}$ Despite that immigrants are overrepresented in lower income groups, they have been shown to have less steep income disparities in a range of health outcomes, including mortality, life expectancy, low birth weight and depression, compared with the gradients observed in Canadian-born individuals. ${ }^{14-17}$ However, recent immigrants of low income have been shown to underuse some health services, such as preventative diagnostic screenings, ${ }^{18}{ }^{19}$ and regardless of social class, the immigrant health advantage has been shown to decline over the duration of their residence. $^{20}$ Differences in the socioeconomic status (SES) gradient in mortality across immigration status may be partly driven by the large proportion of recent immigrants who generally present with a health advantage and reside in lower income groups, ${ }^{14}$ in combination with their shorter exposure to disadvantaged socioeconomic circumstances in their host country. ${ }^{8} 15$

The relationship between SES and mortality in the large immigrant population needs further exploration given the apparent paradox of an immigrant health advantage against a background of socioeconomic inequalities. Specifically, more evidence is needed to distinguish to what extent the immigrant health advantage for all-cause and avoidable mortality extends across SES gradients. Although some Canadian studies have examined differences in immigrant all-cause and causespecific mortality rates by a dimension of SES, ${ }^{14} 2122$ few have studied socioeconomic inequalities among immigrants in relation to avoidable mortality. 
The purpose of the present study was to use comprehensive multilinked mortality files from Canada's most populous province in order to examine all-cause, premature and avoidable mortality rates of immigrants and long-term residents across income levels. These objectives were examined separately in a cohort of males and females to account for differential health and mortality experiences.

\section{METHODS}

\section{Data sources}

The study used multiple population-based vital and demographic databases linked at the Institute for Clinical Evaluative Sciences (ICES). Mortality data were obtained from the Ontario Registrar General-Death files (ORG-D) which contains death records for the province of Ontario from January 1990 to December 2013, including primary and intermediate cause of death information, coded using the International Classification of Disease 9th and 10th revisions, with Canadian enhancements (ICD-9/10-CA). Between 1992 and 2012, 1713705 deaths were registered in the ORG-D and successfully matched to the Ontario Registered Persons database (RPDB) using encrypted health card numbers, representing a 96\% linkage rate. Demographic information, including birth date, sex, postal code and other variables, was obtained from the RPDB, a central population registry file covering the period of April 1990November 2015 for all those eligible for Ontario's health insurance plan and who possess a valid health card. Neighbourhood-level income and education information was attained from various cycles of the Canadian census. The Ontario portion of the Immigration, Refugees and Citizenship Canada (IRCC) Permanent Resident database contains records for 2.9 million individuals, who were granted permanent residency, at the time of landing from 1985 to 2012, and has been linked to the RPDB, with a validation study finding an $86 \%$ linkage rate. ${ }^{23}$ The IRCC database was used to identify immigrants in our study population.

\section{Study population}

We studied deaths registered in the ORG-D between 1 January 1992 and 31 December 2012 that could be linked to a record in the RPDB ( $=1713705)$. Those for whom no geographic information could be obtained, who were not Ontario residents, or were not aged $0-120$ years at the time of death, were excluded $(\mathrm{N}=3625)$. Deaths occurring prior to 2002, records missing a disease classification code for cause of death $(\mathrm{N}=547)$ and those without income information $(\mathrm{N}=4846)$ were also removed from the study cohort (figure 1).

\section{Variable definitions}

Outcome variables

We studied all-cause mortality in addition to deaths amenable to medical care, public health intervention or both, as a measure of health system functioning. Deaths amenable to medical care are deaths that can be avoided even after the development of the condition, in the presence of timely and quality medical care, whereas deaths amenable to public health are those where existing public health measures could prevent the condition from developing. ${ }^{24}$ Deaths were classified as such, based on established classification lists (see online supplementary table S1). ${ }^{112425}$ Finally, we report on premature mortality, defined as death prior to age 75 . All cause of death codes were converted to ICD-9 using established conversion tables.
Figure 1 Study cohort creation. Immigration status of decedents was assigned based on linkage of Institute for Clinical Evaluative Sciences key number (IKN) in the Immigration, Refugee and Citizenship Canada Permanent Resident Database to the IKN in the Registered Persons Database. ORG-D, Ontario Registrar General-Death files.

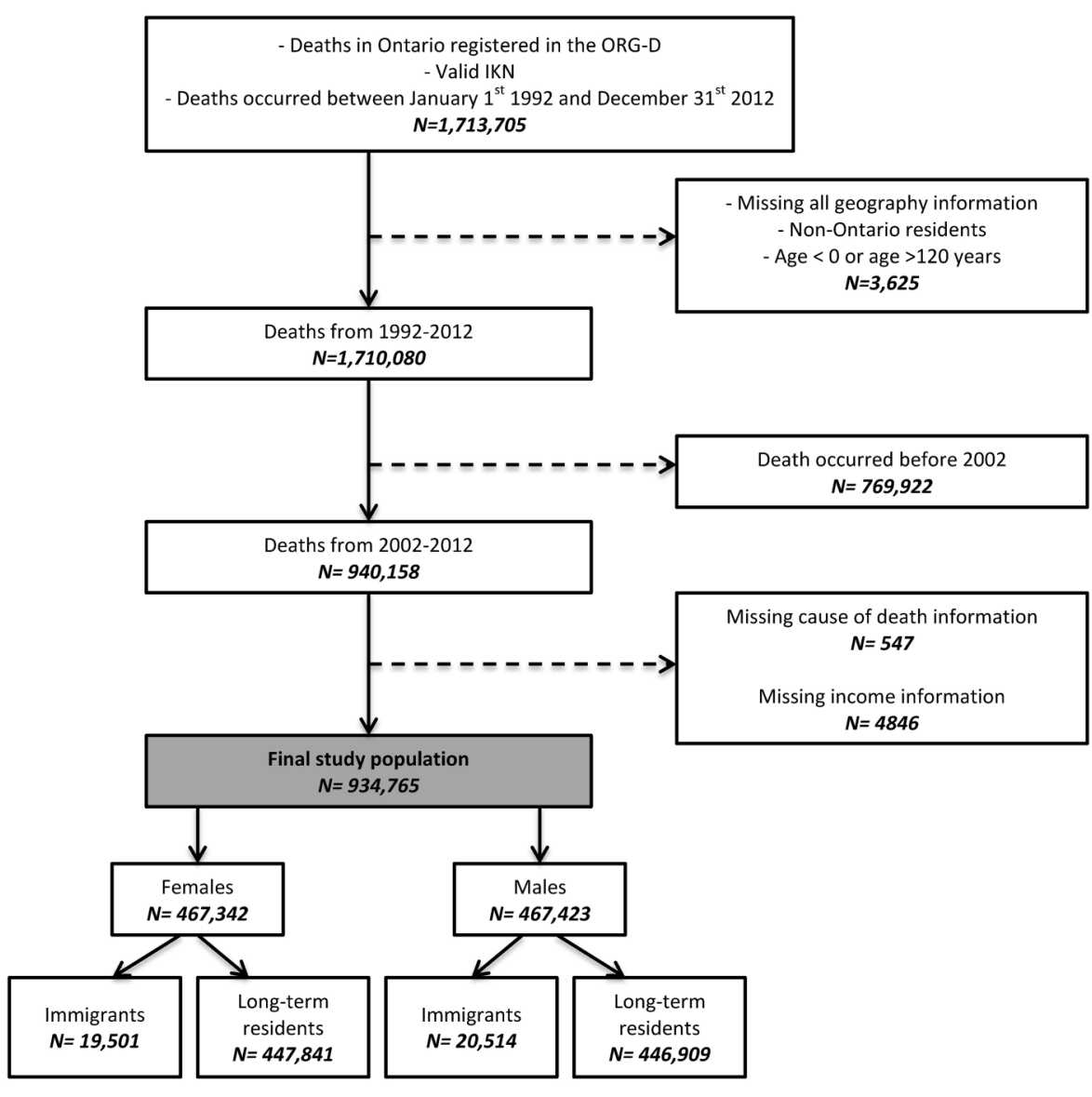


Independent variables

\section{Immigration status}

Individuals were classified as immigrants if their record from the RPDB was successfully linked to a record in the Ontario portion of the IRCC's Permanent Resident database. For the purpose of this study, all other individuals were considered longterm residents. This long-term resident group consisted largely of individuals born in Canada, and contained a small number of immigrants where record linkage between the RPDB and Permanent Resident database was not possible, or who arrived in Canada prior to January 1985.

\section{Socio-demographic variables}

Area-level measures of income and education were used. Area-level income quintile (IQ) information was applied to individual cases according to the dissemination area (DA), which represents the smallest available geographic census area, in which the individual resided. Individuals were assigned to a DA based on their postal code at the time of death. Education information was similarly assigned to individuals based on their DA at time of death and was defined as the proportion of individuals who completed high school in a given DA, grouped into quintiles.

Sex and age information was obtained from the RPDB. Age at time of death was categorised as follows: 0-14, 15-24, 25-34, $35-44,45-54,55-64,65-74,75-85$ and $85+$ years old.

\section{Analysis}

Baseline socio-demographic characteristics were examined across sex, stratified by immigration status. Age-adjusted rates for all-cause mortality, as well as amenable deaths and premature mortality were obtained for immigrants and long-term residents, stratified by sex, as well as across IQ and year using sex-specific negative binomial regression models, or Poisson models in the case a negative binomial model did not converge or overdispersion was not an issue. Further, sex-specific negative binomial regression models were used to test whether time trends for mortality rates varied among immigrants and long-term residents with an interaction term between immigration status and year of death. In separate sex-specific regression models, an interaction term between income and immigration status was included to ascertain whether the association between income and mortality differed according to immigration status. Sensitivity analysis using education as the measure of SES was also performed. In each of the regression models, with the exception of the time trends in which the offset variable was the yearly Ontario population from 2002-2012, the average Ontario population size from 2002-2012 was the offset variable.

Statistical significance was examined at the 0.05 level. All analyses were performed in SAS V.9.3 (SAS Institute, Cary, North Carolina, USA). This study obtained ethics approval from the Research Ethics Boards at the University of Toronto and Sunnybrook Health Sciences Centre.

\section{RESULTS}

\section{Socio-demographic characteristics of the study population}

There were 934765 deaths during the study period, including 19501 deaths among female immigrants and 20514 deaths among male immigrants. All other individuals in the cohort were classified as long-term residents (447841 females and 446909 males) (figure 1). The average age at death for female and male immigrants was $\sim 6$ years younger than that of female and male long-term residents, despite overall mortality rates being lower among immigrants. A higher proportion of immigrants lived in neighbourhoods classified as being in the lowest (poorest) IQ compared with long-term residents $(29.5 \%$ vs $24.0 \%$ for females and $32.4 \%$ vs $23.0 \%$ for males), while the opposite trend was observed for education, in which a greater proportion of immigrants resided in areas in the highest education quintile, compared with long-term residents (table 1).

\section{All-cause, premature and avoidable mortality rates}

All-cause, premature and avoidable mortality rates were higher among long-term residents compared with immigrants (table 2).

The age-adjusted all-cause mortality rate was 60\% lower among male immigrants compared with male long-term residents (rate ratio (RR) $0.40,95 \%$ confidence interval (CI) 0.38 to 0.43 ), and $57 \%$ lower among female immigrants relative to female long-term residents (RR 0.43 , 95\% CI 0.40 to 0.45 ). Similarly, premature mortality rates were $59 \%$ lower among male immigrants (RR 0.41 , 95\% CI 0.39 to 0.44 ), and $58 \%$ lower among female immigrants (RR 0.42 , $95 \%$ CI 0.40 to 0.45 ) compared with male and female long-term residents (table 2).

Table 1 Baseline characteristics of the study population at the time of death, by sex and immigrant status, Ontario, Canada, 2002-2012

\begin{tabular}{|c|c|c|c|c|}
\hline \multirow[b]{3}{*}{ Characteristics } & \multicolumn{2}{|c|}{ Females $(\mathrm{N}=467342)$} & \multicolumn{2}{|c|}{ Males ( $\mathrm{N}=467$ 423) } \\
\hline & $\begin{array}{l}\text { Long-term } \\
\text { residents } \\
(\mathrm{N}=447841)\end{array}$ & $\begin{array}{l}\text { Immigrants } \\
(\mathrm{N}=19501)\end{array}$ & $\begin{array}{l}\text { Long-term } \\
\text { residents } \\
(\mathrm{N}=446 \text { 909) }\end{array}$ & $\begin{array}{l}\text { Immigrants } \\
(\mathrm{N}=20514)\end{array}$ \\
\hline & \multicolumn{4}{|c|}{$\%$ of column total (unless otherwise specified)* } \\
\hline $\begin{array}{l}\text { Age (years) } \\
\text { (mean (SD)) }\end{array}$ & $78.2(15.6)$ & $72.7(17.5)$ & $72.5(16.5)$ & $66.7(18.5)$ \\
\hline \multicolumn{5}{|l|}{ Age (years) } \\
\hline $0-14$ & 0.8 & 0.2 & 1.0 & 0.2 \\
\hline $15-24$ & 0.4 & 1.0 & 1.0 & 2.7 \\
\hline $25-34$ & 0.6 & 2.0 & 1.2 & 3.5 \\
\hline $35-44$ & 1.6 & 5.1 & 2.6 & 6.6 \\
\hline $45-54$ & 4.4 & 8.7 & 6.7 & 12.9 \\
\hline $55-64$ & 8.2 & 10.5 & 12.6 & 14.2 \\
\hline $65-74$ & 14.1 & 16.3 & 20.2 & 17.9 \\
\hline $75-84$ & 29.1 & 27.4 & 31.8 & 25.3 \\
\hline $85+$ & 40.9 & 28.8 & 23.1 & 16.7 \\
\hline \multicolumn{5}{|c|}{ Education quintilet } \\
\hline One & 23.4 & 17.0 & 23.6 & 17.3 \\
\hline Two & 21.9 & 19.0 & 22.3 & 19.5 \\
\hline Three & 20.5 & 21.3 & 20.8 & 22.7 \\
\hline Four & 18.5 & 23.4 & 18.2 & 22.8 \\
\hline Five & 15.0 & 18.7 & 14.4 & 17.2 \\
\hline Unknown & 0.8 & 0.6 & 0.7 & 0.6 \\
\hline \multicolumn{5}{|l|}{ Income quintileł } \\
\hline One & 24.0 & 29.5 & 23.0 & 32.4 \\
\hline Two & 21.2 & 22.7 & 21.5 & 23.2 \\
\hline Three & 19.1 & 19.0 & 19.3 & 19.0 \\
\hline Four & 18.0 & 16.5 & 18.6 & 15.2 \\
\hline Five & 17.9 & 12.4 & 17.8 & 10.3 \\
\hline \multicolumn{5}{|l|}{ Rural status } \\
\hline No & 85.2 & 98.2 & 83.7 & 98.3 \\
\hline Yes & 14.8 & 1.8 & 16.3 & 1.7 \\
\hline
\end{tabular}

*Percentage totals may not add to $100 \%$ due to rounding

tEducation quintile one refers to areas with the smallest proportion of individuals with at least a high school degree; education quintile five refers to areas with the highest proportion of individuals with at least a high school degree. Area level education information was used.

fIncome quintile one represents the lowest quintile (poorest) and quintile five is the highest quintile (richest). Area level income information was utilised. 
Table 2 Age-adjusted mortality rates per 1000 population and rate ratios for all-cause, premature and avoidable mortality, by immigrant status and sex, Ontario, Canada, 2002-2012

\begin{tabular}{|c|c|c|c|c|c|}
\hline \multirow[b]{2}{*}{ Sex; cause of death } & \multicolumn{2}{|l|}{ Immigrants } & \multicolumn{2}{|l|}{ Long-term residents } & \multirow[b]{2}{*}{$\operatorname{RR}(95 \% \mathrm{Cl})^{*}$} \\
\hline & Number of deaths & AAMR $(95 \% \mathrm{Cl})$ & Number of deaths & AAMR $(95 \% \mathrm{Cl})$ & \\
\hline \multicolumn{6}{|l|}{ Males } \\
\hline All-cause & 20514 & $17.2(16.0$ to 18.5$)$ & 446909 & 43.7 (40.8 to 46.7$)$ & 0.40 (0.38 to 0.43$)$ \\
\hline Premature mortality & 11908 & $7.7(7.0$ to 8.5$)$ & 201961 & $19.3(17.7$ to 21.1$)$ & 0.41 (0.39 to 0.44$)$ \\
\hline Amenable to medical care and public health & 1795 & 3.0 (2.6 to 3.5$)$ & 34400 & 8.2 (7.2 to 9.4$)$ & 0.37 (0.35 to 0.39$)$ \\
\hline Amenable to medical care & 1544 & $0.8(0.7$ to 1.0$)$ & 25412 & 2.3 (2.0 to 2.6 ) & $0.38(0.33$ to 0.43$)$ \\
\hline Amenable to public health & 1926 & $1.1(1.0$ to 1.2$)$ & 37711 & $2.8(2.5$ to 3.0$)$ & $0.37(0.35$ to 0.41$)$ \\
\hline \multicolumn{6}{|l|}{ Females } \\
\hline All-cause & 19501 & $11.7(11.0$ to 12.5$)$ & 447841 & $27.9(26.4$ to 29.5$)$ & $0.43(0.40$ to 0.45$)$ \\
\hline Premature mortality & 8546 & $4.8(4.5$ to 5.3$)$ & 134418 & $11.6(10.8$ to 12.5$)$ & $0.42(0.40$ to 0.45$)$ \\
\hline Amenable to medical care and public health & 645 & $0.7(0.6$ to 0.9$)$ & 12227 & $2.4(2.0$ to 2.9$)$ & 0.34 (0.29 to 0.38$)$ \\
\hline Amenable to medical care & 2490 & $1.2(1.1$ to 1.3$)$ & 32501 & 2.7 (2.5 to 2.9 ) & 0.49 (0.47 to 0.52$)$ \\
\hline Amenable to public health & 936 & 0.5 (0.4 to 0.6$)$ & 25946 & 1.6 (1.5 to 1.8$)$ & 0.29 (0.26 to 0.34$)$ \\
\hline
\end{tabular}

Premature mortality is defined as death before the age of 75 .

${ }^{*}$ Reference category is long-term residents.

AAMR, age adjusted mortality rate; $\mathrm{Cl}$, confidence interval; $\mathrm{RR}$, rate ratio.

For avoidable causes of death, among males, age-adjusted mortality rates for immigrants and long-term residents were highest for deaths amenable to medical care and public health (3.0 and 8.2 deaths per 1000 population, respectively), followed by those amenable to only public health $(1.1$ and 2.8 , respectively) and then only medical care interventions (0.8 and 2.3, respectively) (table 2). Among females, the age-adjusted mortality rates for immigrants and long-term residents were highest for deaths amenable to only medical care (1.2 and 2.7 per 1000 population, respectively), followed by deaths amenable to medical care and public health (0.7 and 2.4, respectively) and finally those amenable to public health interventions alone $(0.5$ and 1.6 , respectively) (table 2 ).

\section{Trends in all-cause, premature and avoidable mortality rates (2002-2012)}

Trends from 2002 to 2012 show significant declines in all-cause mortality rates for immigrants and long-term residents, and significant declines in premature mortality rates for long-term residents only (table 3). During this time period, all-cause mortality rates decreased $11 \%$ for male immigrants (RR 0.89 , CI 0.82 to 0.98 ) and female immigrants (RR 0.89 , CI 0.81 to 0.98 ), while long-term residents experienced a $13 \%$ decrease among males (RR 0.87, CI 0.82 to 0.91) and females (RR 0.87, CI 0.82 to $0.91)$. The decline in premature mortality rates during this time period was $14 \%$ among female long-term residents (RR 0.86, CI 0.82 to 0.90 ) and $13 \%$ among male long-term residents (RR 0.87 , CI 0.83 to 0.91$)$.

Trends in avoidable causes of death from 2002 to 2012 (table 3 ) indicate that for deaths amenable to public health and medical care, there was a statistically significant $28 \%$ decrease among male immigrants (RR 0.72 , CI 0.58 to 0.91 ), $30 \%$ decrease among male long-term residents (RR 0.70 , CI 0.65 to 0.75 ), and $33 \%$ decrease among female long-term residents (RR 0.67 , CI 0.60 to 0.74 ). The decrease among immigrant females during this time period was not statistically significant. Similarly, female and male immigrants did not experience significant declines in deaths amenable to medical care or public health. However, long-term residents experienced a 16\% (males) and $19 \%$ (females) significant decline in deaths amenable to medical care, as well as a $19 \%$ (males) and $10 \%$ (females) significant decline in deaths amenable to public health. While the declines in all-cause mortality and deaths amenable to both were slightly steeper among long-term residents, it was not significantly different than the declines experienced by immigrants.

\section{All-cause, premature and avoidable mortality rates by IQ}

With increasing IQ there was a downward gradient in age-adjusted all-cause, premature and avoidable mortality rates, for immigrants and long-term residents, within the male and female cohorts (table 4). These gradients were more pronounced for long-term residents compared with immigrants. All-cause age-adjusted mortality rates per 1000 population were lowest in the highest (richest) IQ compared with the lowest (poorest) IQ for immigrants (males: IQ5: 13.32, IQ1: 20.18; females: IQ5: 9.88, IQ1: 12.51) and long-term residents (males: IQ5: 33.25, IQ1: 57.67; females: IQ5: 22.31, IQ1: 36.76). Similarly, male immigrants and long-term residents in the lowest IQ presented with $63 \%$ and $94 \%$ higher premature mortality rates, respectively, compared with their male counterparts in the highest IQ (immigrants: RR 1.63, 95\% CI 1.40 to 1.91 ; longterm residents: RR 1.94, 95\% CI 1.71 to 2.21). Among females, immigrants and long-term residents in the lowest IQ had a $37 \%$ and $88 \%$ greater rate of premature death, respectively, compared with their female counterparts in the highest IQ (immigrants: RR 1.37 , 95\% CI 1.23 to 1.54 ; long-term residents: RR 1.88 , 95\% CI 1.74 to 2.02 ). The association between income and age-adjusted all-cause and premature mortality differed across immigration status for females ( $p$-interaction $=0.0025$, p-interaction $<0.0001$, respectively), and did not differ significantly for males (table 4).

A similar pattern was found for all-cause mortality, premature mortality and deaths amenable to public health measures, in that female immigrants had lower age-adjusted mortality rates across all income levels, followed by male immigrants, then female long-term residents and finally male long-term residents (table 4). A notable difference was found for deaths amenable to public health and medical care such that female immigrants and long-term residents presented with lower mortality rates across all IQs compared with their male counterparts. The pattern also diverged for deaths amenable to medical care, as across all income levels, female immigrants presented with higher 
Table 3 Rate ratios and $95 \%$ Cls quantifying yearly trends in all-cause, premature and avoidable mortality, by sex and immigration status, Ontario, Canada, 2002-2012

\begin{tabular}{|c|c|c|c|c|c|c|c|c|}
\hline \multirow[b]{3}{*}{ Cause of death; year } & \multicolumn{4}{|c|}{ Females } & \multicolumn{4}{|c|}{ Males } \\
\hline & \multicolumn{2}{|c|}{ Long-term residents } & \multicolumn{2}{|c|}{ Immigrants } & \multicolumn{2}{|c|}{ Long-term residents } & \multicolumn{2}{|c|}{ Immigrants } \\
\hline & $\mathbf{R R}^{*}$ & $95 \% \mathrm{Cl}$ & $\mathbf{R R}^{*}$ & $95 \% \mathrm{Cl}$ & $\mathbf{R R}^{*}$ & $95 \% \mathrm{Cl}$ & $\mathbf{R R}^{*}$ & $95 \% \mathrm{Cl}$ \\
\hline \multicolumn{9}{|l|}{ All-cause } \\
\hline 2012 & 0.87 & 0.82 to 0.91 & 0.89 & 0.81 to 0.98 & 0.87 & 0.82 to 0.91 & 0.89 & 0.82 to 0.98 \\
\hline 2007 & 0.94 & 0.89 to 0.99 & 0.98 & 0.89 to 1.08 & 0.95 & 0.90 to 1.00 & 0.98 & 0.90 to 1.08 \\
\hline p-interactiont & 0.61 & & & & 0.94 & & & \\
\hline \multicolumn{9}{|c|}{ Amenable to medical care and public health } \\
\hline 2012 & 0.67 & 0.60 to 0.74 & 0.72 & 0.50 to 1.06 & 0.70 & 0.65 to 0.75 & 0.72 & 0.58 to 0.91 \\
\hline 2007 & 0.83 & 0.75 to 0.92 & 0.77 & 0.52 to 1.15 & 0.84 & 0.79 to 0.90 & 0.86 & 0.68 to 1.09 \\
\hline p-interaction $\dagger$ & 0.34 & & & & 0.88 & & & \\
\hline \multicolumn{9}{|c|}{ Amenable to medical care } \\
\hline 2012 & 0.81 & 0.76 to 0.86 & 1.07 & 0.88 to 1.31 & 0.84 & 0.77 to 0.92 & 0.89 & 0.69 to 1.14 \\
\hline 2007 & 0.94 & 0.89 to 1.00 & 1.25 & 1.02 to 1.53 & 0.96 & 0.88 to 1.04 & 0.88 & 0.68 to 1.15 \\
\hline p-interactiont & 0.15 & & & & 0.92 & & & \\
\hline \multicolumn{9}{|c|}{ Amenable to public health } \\
\hline 2012 & 0.90 & 0.85 to 0.96 & 1.00 & 0.73 to 1.37 & 0.81 & 0.76 to 0.86 & 0.94 & 0.75 to 1.17 \\
\hline 2007 & 0.97 & 0.92 to 1.04 & 0.93 & 0.66 to 1.30 & 0.93 & 0.87 to 0.99 & 1.04 & 0.83 to 1.30 \\
\hline p-interactiont & 0.94 & & & & 0.45 & & & \\
\hline \multicolumn{9}{|l|}{ Premature mortality } \\
\hline 2012 & 0.86 & 0.82 to 0.90 & 0.99 & 0.88 to 1.11 & 0.87 & 0.83 to 0.91 & 0.91 & 0.83 to 1.01 \\
\hline 2007 & 0.94 & 0.90 to 0.98 & 1.05 & 0.93 to 1.18 & 0.96 & 0.92 to 1.00 & 0.97 & 0.88 to 1.07 \\
\hline p-interactiont & 0.21 & & & & 0.37 & & & \\
\hline
\end{tabular}

Data for all years from 2002 to 2012 are not shown.

Models were adjusted for age and income quintile.

* Reference year was 2002.

†Interaction was assessed between year and immigration status.

$\mathrm{Cl}$, confidence interval; $\mathrm{RR}$, rate ratio.

age-adjusted mortality rates than male immigrants, and female long-term residents had higher mortality rates compared with their male long-term resident counterparts. The income gradient differed between female immigrants and long-term residents for deaths amenable to medical care and public health ( $p$-interaction $=0.0178)$, as well as for deaths amenable to medical care $(p$-interaction $=0.0027)$. The interaction was not significant across immigration status for males (table 4). Similar trends were observed when education, instead of income, was used as the measure of SES (see online supplementary table S2).

\section{DISCUSSION}

This study linked population-level mortality files to examine rates of all-cause, premature and avoidable deaths among immigrants and long-term residents in Canada's largest province, with a focus on socioeconomic gradients of mortality across immigration status. Findings spanning the period of 2002 to 2012 suggest that overall, immigrants present with lower rates of all-cause, premature and avoidable mortality compared with long-term residents. However, time trends suggest that longterm residents experienced greater declines in mortality compared with immigrants. Furthermore, mortality income gradients differed for immigrants and long-term residents across immigration status. While previous studies report mortality rates among Canadian immigrants, a systematic examination of income inequalities in mortality across immigration status is lacking, especially for avoidable causes of death.

This study confirms an immigrant health advantage pertaining to mortality, ${ }^{7-9}$ and corroborates the historical Canadian trend of a female mortality advantage. ${ }^{26}$ Also, the advantage in all- cause and premature mortality among male immigrants over male long-term residents was slightly more pronounced than the advantage among female immigrants over female long-term residents; consistent with previous studies. ${ }^{79}$

We found that the immigrant and female mortality advantage extended to causes of death amenable to public health and medical care. An exception to the female mortality advantage was identified for causes of death amenable to only medical care and public health, which contrasted findings for immigrants and long-term residents in a larger Canadian study. ${ }^{12}$ Specifically, for causes amenable to medical care, we found higher age-adjusted mortality rates among female immigrants compared with male immigrants and among female long-terms residents compared with male long-term residents. This finding may illustrate persistent barriers for female immigrants around access and usage of primary care services in Ontario. ${ }^{27}{ }^{28}$ Additionally, for causes amenable to public health, female long-term residents were found to present with greater mortality rates compared with male immigrants. This reveals an immigrant mortality advantage and potential differences in preventative behaviours between male immigrants and female long-term residents of Ontario. For example, male immigrants have shown lower smoking prevalence than female Canadian-born residents. ${ }^{2}$

Notably, long-term residents experienced substantial declines in premature and avoidable mortality over the study period, whereas declines among immigrants were not as steep, except for causes amenable to public health and medical care among males. It is possible that over this time period, long-term residents may have benefitted more from healthcare and preventative measures, compared with immigrants. It is also plausible 


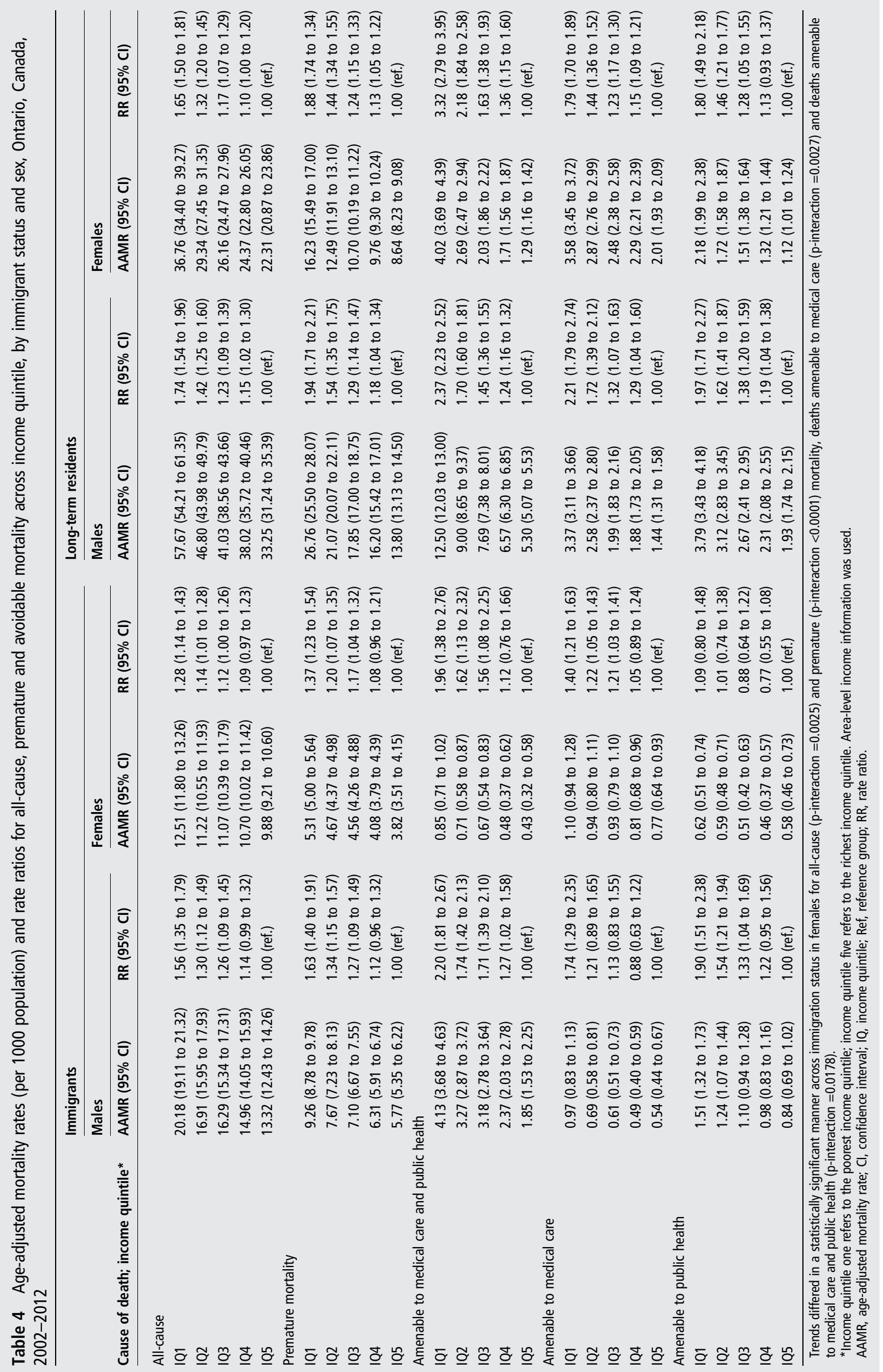


that relative to long-term residents, mortality declines over time among immigrants were allayed by their already low-mortality rates at baseline, thus producing a floor effect.

Irrespective of immigration status an income gradient in mortality exists favouring those with progressively higher incomes, supporting previous findings. ${ }^{14} 222930$ Moreover, the income differentials observed in our study were generally steeper for long-term residents than for immigrants. The lesser gradient for immigrants may be influenced by the generally good health of recent immigrants who reside in lower IQs, in accordance with the healthy immigrant effect. ${ }^{14}$ Educational attainment may also have served as a protective factor, blunting the income mortality gradient among immigrants. This may be especially true given that a greater proportion of immigrants compared with longterm residents in our study were classified as residing in areas in the lowest income and highest education quintiles.

\section{Strengths and limitations}

A strength of the study was the use of a population data file (ORG-D) encompassing all registered deaths in Ontario, linked to the IRCC file, ensuring accurate recording of immigration status for those who immigrated into Canada since 1985. Our study population contains the largest proportion of immigrants in all Canadian provinces and the large number of deaths enabled us to examine the persistence of an income mortality gradient across immigration status and over a range of income levels. Furthermore, the fact that the cohort originated from a province with a large and diverse immigrant population, aids in the generalisability of the findings to other settings.

Despite these strengths, some limitations exist. First, due to the nature of the IRCC Permanent Resident database, some immigrants may have been misclassified as long-term residents, such as those who arrived prior to 1985 . Nevertheless, those who immigrated prior to 1985 would have resided in Canada for at least 18 years prior to the initiation of the study period and research demonstrates that over the years of residence, the socioeconomic characteristics and health of immigrants tends to resemble that of the Canadian-born population. ${ }^{8}{ }^{31}$ Second, we used macro-level indicators of individual income, specifically neighbourhood-level income, which may have attenuated the mortality-income gradient observed in our study. ${ }^{32}$ We were still able to observe important mortality gradients in this study, and ecological indicators are important in understanding the context of SES gradients among immigrants. Third, we were unable to account for the role, if any, that behavioural and lifestyle factors, such as smoking and alcohol consumption, would have had in explaining the immigrant mortality advantage observed; these effects should be explored in future studies. Finally, it was not possible to identify cases of mortality for those immigrants, including those who immigrated prior to 1985 , who died outside of Canada (eg, the salmon bias). ${ }^{33}$ If present, this would have resulted in artificially lower mortality rates among immigrants in our study.

\section{Conclusions}

This study illustrated that income disparities exist in all-cause, premature and avoidable mortality, irrespective of immigration status. Findings demonstrated a trend of significant declines in mortality rates for long-term residents, but not for immigrants. Differences in avoidable mortality suggest that there may be differences in preventative health behaviours and access to healthcare services. Findings support the need to better examine factors that drive these inequalities differentially across and within immigration status, which can inform where and for whom improvements to health services and public health efforts are needed to close the mortality gap and ensure equitable health for all.

\section{What is already known on this subject?}

- There exists a paradox in which immigrants present with lower mortality rates attributed to avoidable causes despite being more likely to live in more arduous socioeconomic conditions, which is a strong social determinant of health. Little is known about the extent of the immigrant health advantage for all-cause and avoidable mortality and if or how the socioeconomic gradient for mortality differs according to immigration status, especially for avoidable causes of death.

\section{What this study adds?}

- The immigrant health advantage extends to all-cause, premature and avoidable mortality.

- Income disparities exist in all-cause, premature and avoidable mortality, irrespective of immigration status but these differences are more pronounced in long-term residents.

- There exist trends over time of significant declines in mortality rates among long-term residents, but not for immigrants.

- The findings support the need to better examine the factors that drive these inequalities to ensure equitable health for the totality of the population.

Acknowledgements This study was supported by the Institute for Clinical Evaluative Sciences (ICES), which is funded by an annual grant from the Ontario Ministry of Health and Long-Term Care (MOHLTC). The opinions, results and conclusions reported in this paper are those of the authors and are independent from the funding sources. No endorsement by ICES or the Ontario MOHLTC is intended or should be inferred. These data sets were linked using unique encoded identifiers and analysed at ICES. Parts of this material are based on data and information compiled and provided by Immigration, Refugees, and Citizenship Canada and Service Ontario.

Contributors LR, MU and AMK conceived the manuscript. AMK, KK and SYC prepared data and ran all analyses. DH, LR, MU and CB contributed to the analytic plan and interpretation. AK and LR drafted the manuscript and all authors edited and critically reviewed the final content.

Funding This study was funded by the Canadian Institutes for Health Research Operating Grant (FRN-142498). LR is supported by a Canada Research Chair in Population Health Analytics.

\section{Competing interests None declared.}

Ethics approval This study received ethics approval from the University of Toronto's Health Sciences Research Ethics Board and the institutional review board at Sunnybrook Health Sciences Centre, Toronto, Canada.

Provenance and peer review Not commissioned; externally peer reviewed.

Data sharing statement The data set used in this study is held securely in coded format at ICES. Although data sharing agreements prohibit ICES from making the data set publicly available, access may be granted to those who meet the conditions for confidential access, available at http://www.ices.on.ca/Data-Services.

Open Access This is an Open Access article distributed in accordance with the Creative Commons Attribution Non Commercial (CC BY-NC 4.0) license, which permits others to distribute, remix, adapt, build upon this work non-commercially, and license their derivative works on different terms, provided the original work is 
properly cited and the use is non-commercial. See: http://creativecommons.org/ licenses/by-nc/4.0/

\section{REFERENCES}

1 Immigration and ethnocultural diversity in Canada (99-010-X). (https://www12. statcan.gc.ca/nhs-enm/2011/as-sa/99-010-x/99-010-x2011001-eng.cfm).

2 Pérez $C$. Health status and health behaviour among immigrants. Health Rep 2002;13:1-12.

3 Ali JS, McDermott S, Gravel RG. Recent research on immigrant health from statistics Canada's population surveys. Can J Public Health 2004;95:19-113.

4 Newbold K. Chronic conditions and the healthy immigrant effect: evidence from Canadian immigrants. Journal of Ethnic and Migration Studies 2006;32:765-84.

5 McDonald J, Kennedy S. Insights into the 'healthy immigrant effect': health status and health service use of immigrants to Canada. Social Sciences Medicine 2004;59:1613-27.

6 Kennedy S, Kidd M, McDonald J, et al. The healthy immigrant effect: patterns and evidence from four countries. Journal of International Migration and Integration 2015;16:317-32.

$7 \mathrm{Ng} \mathrm{E}$. The healthy immigrant effect and mortality rates. Health Rep 2011;22:25-9.

8 Omariba D, Ng E, Vissandjee B. Differences between immigrants at various durations of residence and host population in all-cause mortality, Canada 19912006. Popul Stud (Camb) 2014;68:339-57.

9 DesMeules M, Gold J, McDermott $\mathrm{S}$, et al. Disparities in mortality patterns among Canadian immigrants and refugees, 1980-1998: Results of a National Cohort Study. J Immigr Health 2005;7:221-32.

10 Dunn JR, Dyck I. Social determinants of health in Canada's immigrant population: results from The National population health survey. Soc Sci Med 2000;51:1573-93.

11 Nolte $E$, McKee M. Measuring the health of nations: analysis of mortality amenable to health care. BMJ 2003;327:1129.

12 Omariba DW. Immigration, ethnicity, and avoidable mortality in Canada, 19912006. Ethn Health 2015;20:409-36.

13 Picot G, Hou F. Immigration, low income and income inequality in Canada: what's new in the 2000s? Analytical Studies Branch Research Paper Series Catalogue no 11F0019M 2014;364:1-41.

14 Stratton J, Mowat DL, Wilkins R, et al. Income disparities in life expectancy in the city of Toronto and region of Peel, Ontario. Chronic Dis Inj Can 2012;32:208-15.

15 Urquia ML, Frank JW, Glazier RH, et al. Birth outcomes by neighbourhood income and recent immigration in Toronto. Health Rep 2007;18:21-30.

16 Smith KL, Matheson Fl, Moineddin R, et al. Gender, income and immigration differences in depression in Canadian urban centres. Can J Public Health 2007;98:149-53.

17 Auger N, Hamel D, Martinez J, et al. Mitigating effect of immigration on the relation between income inequality and mortality: a prospective study of 2 million Canadians. J Epidemiol Community Health 2012;66:e5.
18 Glazier RH, Creatore MI, Gozdyra P, et al. Geographic methods for understanding and responding to disparities in mammography use in Toronto, Canada. J Gen Intern Med 2004;19:952-61.

19 Lofters AK, Moineddin R, Hwang SW, et al. Low rates of cervical cancer screening among urban immigrants: a population-based study in Ontario, Canada. Med Care 2010;48:611-8.

20 Vang Z, Sigouin J, Flenon A, et al. Are immigrants healthier than native-born Canadians? A systematic review of the healthy immigrant effect in Canada. Ethn Health Epub ahead of print: 3 Nov 2016. doi:10.1080/13557858.2016.1246518

21 Tjepkema M, Wilkins $R$, Long $A$. Cause-specific mortality by income adequacy in Canada: a 16-year follow-up study. Health Rep 2013;24:14-22.

22 Tjepkema M, Wilkins $\mathrm{R}$, Long A. Socio-economic inequalities in cause-specific mortality: a 16-year follow-up study. Can J Public Health 2013;104:e472-8.

23 Guttmann A, Chiu M, Lebenbaum M, et al. Describing the linkages of the citizenship and immigration Canada permanent pesident data and vital statistics-death registry to Ontario's administrative health databases. International Population Data Linkage Conference: 2016; Wales, UK: International Journal of Population Data Science, 2016.

24 James PD, Wilkins R, Detsky AS, et al. Avoidable mortality by neighbourhood income in Canada: 25 years after the establishment of universal health insurance. J Epidemiol Community Health 2007;61:287-96.

25 James PD, Manuel DG, Mao Y. Avoidable mortality across Canada from 1975 to 1999. BMC Public Health 2006;6:137-46.

26 Bourbeau R, Ouellette N. Trends, patterns, and differentials in Canadian mortality over nearly a century (1921-2011). Canadian Studies in Population 2016;18:841-53.

27 Asanin J, Wilson K. "I spent nine years looking for a doctor": exploring access to health care among immigrants in Mississauga, Ontario, Canada. Soc Sci Med 2008;66:1271-83.

28 Bissonnette L, Wilson K, Bell S, et al. Neighbourhoods and potential access to health care: the role of spatial and aspatial factors. Health Place 2012;18:841-53.

29 Lynch J, Harper S, Kapan GA, et al. Association between income inequality and mortality among US states: the importance of time period and source of income data. Am J Public Health 2005;95:1424-30.

30 Mclntosh CN, Finès $P$, Wilkins $R$, et al. Income disparities in health-adjusted life expectancy for Canadian adults, 1991 to 2001. Health Rep 2009;20:55-64.

31 Thomas D, Rappal J. Employment stability and the adjustment of immigrants: an examination of data from the survey of labour and income dynamics. The Income and Labour Dynamics Working Paper Series. vol. Catalogue No. 98-01;1998.

32 Pampalon R, Hamel D, Gamache P. Comparison of individual and area-based socio-economic data for monitoring social inequalities in health. Health Rep 2009;20:85-94.

33 Urquia ML, Gagnon AJ. Glossary: migration and health. J Epidemio/ Community Health 2011;65:467-72. 